\title{
Field laser applications in industry and research
}

\author{
F. D'Amato $\cdot$ A. Fried
}

Published online: 26 February 2015

(C) Springer-Verlag Berlin Heidelberg 2015

The fourth edition of FLAIR, Field Laser Applications in Industry and Research, was held on May 5 until May 9, 2014, in Pratolino, Firenze, Italy, the same venue where the FLAIR series was started in 2007. The enthusiasm for this edition has been dampened by the sudden passing of Dr. Peter Werle, one of the two co-chairmen, on September 6, 2013, during the organization of the meeting. For an obituary of Dr. Werle see [1].

This event obviously affected the organization of the Conference, including its schedule. We wanted to pay Peter Werle a special tribute, but in such a way to transform this remembrance into a positive event. To this end, the conference began with a special session that not only highlighted Peter Werle as a great colleague and friend but also as a visionary who has made numerous significant contributions to quantitative analysis, including noise analysis, employing tunable IR spectroscopy.

Dr. Werle was the first to introduce the Allan variance concept [2] to spectroscopic analysis, in order to assess the noise and stability of the particular spectrometer being employed. Given the pioneering nature of this contribution, the organizing committee recommended that all future references to Allan variance measurements of optical analytical instruments be referred to as "Allan-Werle" variance.

Moreover, an award has been dedicated to him, aimed to recognize an outstanding early career scientist who best exemplifies Peter Werles scientific attributes, such

F. D'Amato $(\square)$

CNR, National Institute of Optics, Largo E. Fermi 6,

50125 Florence, Italy

e-mail: francesco.damato@ino.it

A. Fried

Institute of Arctic and Alpine Research (INSTAAR), University

of Colorado, 1560 30th Street, Boulder, CO 80303, USA as: formulation of creative new ideas, intellectual honesty, extreme attention to details, inquisitiveness, strong mathematical and engineering backgrounds, a proven track record of success, and achieving such success by questioning existing thinking and/or technologies.

The prize has been awarded to Dr. Gerard Wysocki, for his overall excellent track record exemplifying, in practically all aspects, the above-mentioned criteria. Dr. Wysocki's interests focus on the development of laserbased spectroscopic systems for chemical sensing, often using innovative and novel detection techniques. He has been early to engage in the development of widely tunable mid-infrared external cavity quantum cascade lasers (EC-QCLs) for high-resolution spectroscopic applications in chemical analysis that, for example, were used with the background-free Faraday rotation detection of nitric oxide and the hydroxyl radical in biofuel combustion diagnostics. A particularly innovative development has been that of the chirped laser dispersion spectroscopy technique, and a number of derived techniques, which enabled, among other things, sensitive open path detection of atmospheric nitric oxide. The latter is also a nice example of his willingness to challenge "the common wisdom" in using the practice of measuring molecular absorption rather than optical dispersion. Other examples of his dedication to apply advanced spectroscopic techniques to real-world problems are his involvement in the development of biomedical instrumentation for nitric oxide isotopes in metabolic studies, and the development of low-power, miniature spectroscopic tracegas sensors for wirelessly communicating distributed sensor networks. Some of these activities are highlighted by one of the articles from Dr. Wysocki and his group in this special issue [3].

FLAIR offers a guided tour along the different rings of the chain of knowledge and competences, from the 


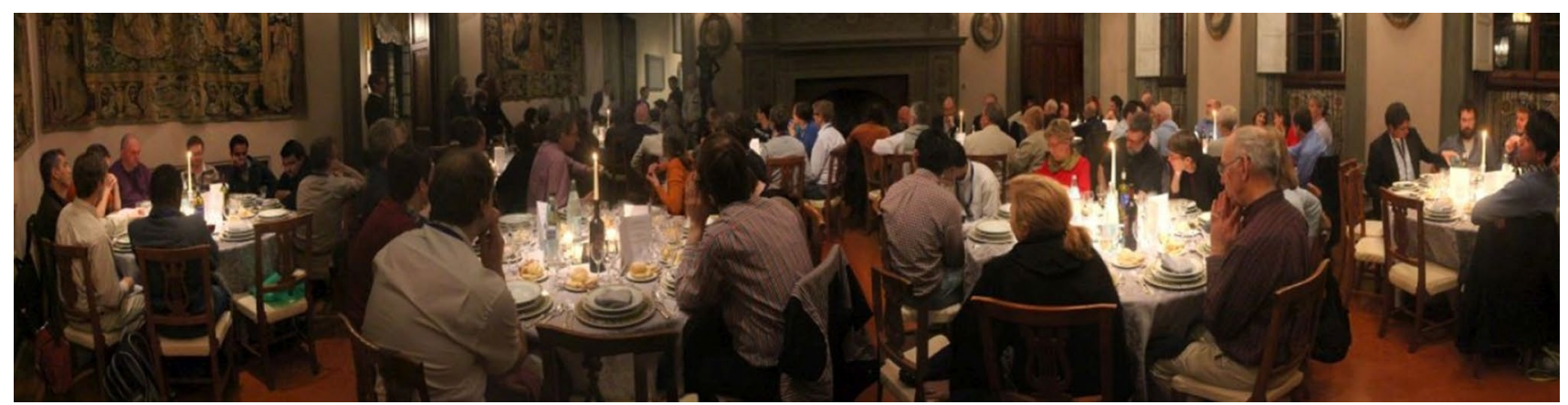

Fig. 1 Dinner at Villa di Maiano (courtesy of B. McManus)

development of new material and basic components, toward practical applications, ending with the requests of final users. In this edition, we started with the novelties about $\mathrm{THz}$ quantum cascade (A. Tredicucci) and mid-infrared, high tunability, interband cascade (M. Kamp) laser sources. We spanned several detection techniques and components: QEPAS (V. Spagnolo), fiber optic strain detectors (H.-P. Loock), Cavity Ring-Down (J. Burkart), hollow waveguides (B. Mizaikoff). End users provided fundamental questions and requirements regarding instrument performance. For example, V. Masson-Delmotte urged better performances from water isotopic ratio analyzers, J. Orphal required accurate spectroscopic measurements for calibration of satellite sensors, F. Meixner listed, in the last talk of his scientific career, the open questions in flux measurements.

Despite the tragedy, which affected the organization of the meeting, the interest in the conference did not fall: besides the 12 invited talks, there were 18 talks by sponsoring firms, 30 contributed talks and 65 posters. We had 164 participants and 21 sponsors.

In the FLAIR meetings, the contribution of the sponsors is not only a financial one, as they share with all the attendees their most recent innovations. For this reason, a session is always devoted to them. In this edition, we heard about advances in laser sources by ALPES LASERS, NTT-EL, NANOPLUS, EOS PHOTONICS, DAYLIGHT SOLUTIONS, VERTILAS, PHILIPS TECHNOLOGIE-ULM PHOTONICS, TOPTICA and HAMAMATSU. LASERCOMPONENTS dealt with different kinds of detectors and detector arrays.

Devices for environmental monitoring were illustrated by THERMO FISHER, LOS GATOS, AERODYNE, PSI and LI-COR, while industrial applications were dealt with by AXETRIS and SENSOR SENSE.

Finally, Gestione SILO described and exhibited a very interesting optical component, namely a 1-mm-thick mirror blank, $40 \mathrm{~cm}$ diameter, for future spaceborne applications of adaptive optics.

As usual, FLAIR offered some social events, which were related to "Dante Alighieri," the Italian poet who, at the end of the 13th century, started the modern Italian language. On thursday, we had dinner in Villa di Maiano, the set of the movie "A room with a view" (which was awarded three Academy Awards in 1987). During this dinner (Fig. 1), the organizers communicated the name of the winner of the Peter Werle award.

Besides thanking our sponsors for financial support, invited speakers for keeping high the scientific level of the conference, and the advisory board, we thank the scientific secretariat, Dr. Silvia Viciani (CNR-INO), the local organizers, Dr. Mario Siciliani de Cumis (CNR-INO) and Dr. Stefan Thiel (KIT-IMK), and Mrs. Roberta Parenti (CNRINO) for her assistance about financial and burocratic issues.

We would like to thank also Dr. Hans-Peter Schmidt, director of KIT IMK-IFU, Garmisch-Partenkirchen, where Dr. Werle worked until his very last day, for his support to the organization of FLAIR 2014.

A particular mention goes to Prof. Erik Kerstel (Universit Joseph Fourier, Grenoble, F), who contributed to several features of the organization after Dr. Werle's passing. We are very pleased to announce that the FLAIR series will continue and that he will join Dr. D'Amato as a co-chairman for the next meetings.

\section{References}

1. F. D'Amato, A. Fried, E. Kerstel, Obituary for Dr Peter Werle. Isot Environ Health Stud 49(4), 575-578 (2013)

2. D.W. Allan, Statistics of atomic frequency standards. Proc IEEE 54, 221 (1966)

3. M. Nikodem, G. Plant, D. Sonnenfroh, G. Wysocki, Openpath sensor for atmospheric methane based on chirped laser dispersion spectroscopy. Appl. Phys. B (2015). doi:10.1007/ s00340-014-5938-3 